\title{
Effects of Nitric Oxide Synthase Inhibitors on Gastric Alkaline Secretion in Rats
}

\author{
Koji Takeuchi, Tomohisa Ohuchi, Hiroki Miyake, Hiromi Sugawara and Susumu Okabe \\ Department of Applied Pharmacology, Kyoto Pharmaceutical University, Misasagi, Yamashina, Kyoto 607, Japan \\ Received July 8, 1992 Accepted September 19, 1992
}

\begin{abstract}
The effects of $N^{G}$-nitro-L-arginine methyl ester (L-NAME), the nitric oxide (NO) synthase inhibitor, on gastric $\mathrm{HCO}_{3}{ }^{-}$secretion were examined in anesthetized rats. Intravenous administration of L-NAME $(1,2.5,5 \mathrm{mg} / \mathrm{kg})$ increased $\mathrm{HCO}_{3}{ }^{-}$secretion in a dose-related manner. This effect of L-NAME was mimicked by $N^{G}$-mono-methyl-L-arginine $(50 \mathrm{mg} / \mathrm{kg}$, i.v.) and was antagonized significantly by concurrent administration of $\mathrm{L}$-arginine but not $\mathrm{D}$-arginine $(200 \mathrm{mg} / \mathrm{kg}$, i.v.). These results indicate that gastric $\mathrm{HCO}_{3}{ }^{-}$secretion is stimulated by inhibition of $\mathrm{NO}$ biosynthesis.
\end{abstract}

Keywords: Nitric oxide synthase inhibitor, $\mathrm{HCO}_{3}{ }^{-}$secretion, Stomach

Nitric oxide (NO), synthesized from the semi-essential amino acid L-arginine by NO synthase in the vascular endothelium is now established to mediate various biological actions under physiological conditions (1). Recent studies have shown that NO also plays an important role in the modulation of the gastric mucosal integrity by interacting with other protective mediators $(2,3)$. Regulation of gastric mucosal blood flow is considered to be the major mechanism responsible for the mucosal protective action of NO $(2,4)$, yet the influences of the inhibition of NO biosynthesis on other defensive factors such as $\mathrm{HCO}_{3}{ }^{-}$secretion has not been studied. In the present study, we thus examined the effects of the NO synthase inhibitor on $\mathrm{HCO}_{3}{ }^{-}$secretion in the rat stomach using $N^{G}$-nitro-L-arginine as the methyl ester (L-NAME) and characterized these effects in relation to endogenous NO.

Male Sprague Dawley rats $(230-250 \mathrm{~g})$, kept in individual cages with raised mesh bottoms, were deprived of food but allowed free access to tap water for $18 \mathrm{hr}$ before the experiments. The animals were anesthetized with urethane $(1.25 \mathrm{~g} / \mathrm{kg}$, i.p.; Tokyo Kasei); and then the stomach was exposed, mounted on a chamber (exposed area: $3.14 \mathrm{~cm}^{2}$ ), and perfused with saline that was gassed with $100 \% \mathrm{O}_{2} . \mathrm{HCO}_{3}{ }^{-}$secretion was determined at $\mathrm{pH} 7.0$ by continuous titration of the perfusate with $10 \mathrm{mM} \mathrm{HCl}$ under acid inhibition by omeprazole $(60 \mathrm{mg} / \mathrm{kg}$, i.p.). In some cases, the stomach was perfused with acidified saline $(\mathrm{pH} 4.5)$ at the rate of 1 $\mathrm{ml} / \mathrm{min}$, and the $\mathrm{pH}$ of the perfusate and transmucosal potential difference (PD) were monitored simultaneously with arterial blood pressure (BP). The $\mathrm{pH}$ was measured by a flow type glass electrode (Horiba, Model 6901-25T), while PD was determined by using two agar bridges, one positioned in the chamber and the other in the abdominal cavity (5). BP was monitored via the femoral artery by a pressure transducer and amplifier system (Nihon Kohden). $N^{G}$-nitro-t-arginine methyl ester (L-NAME: Sigma), $\quad N^{G}$-monomethyl-L-arginine (L-NMMA: Sigma) and prostaglandin $\mathrm{E}_{2}\left(\mathrm{PGE}_{2}\right.$, Funakoshi) were given i.v. after basal secretion had stabilized. In some cases, L- or D-arginine (Wako) was given i.v. $5 \mathrm{~min}$ before administration of L-NAME. Data are presented as the mean \pm S.E. from 5-6 rats. Statistical analyses were performed by the two-tailed Dunnett's multiple comparison test, and values of $\mathrm{P}<0.05$ were regarded to indicate a significant difference.

In the animals pretreated with omeprazole, the gastric mucosa mounted on a chamber and perfused with acidified saline ( $\mathrm{pH} 4.5)$ generated a PD of $-40-$ $-45 \mathrm{mV}$ (mucosa negative), secreted alkali to keep the luminal $\mathrm{pH}$ at $4.8-5.2$, and $\mathrm{BP}$ was maintained around $90-100 \mathrm{mmHg}$. Intravenous administration of L-NAME at $5 \mathrm{mg} / \mathrm{kg}$ produced a marked increase of $\mathrm{pH}$ with a slight decrease in $\mathrm{PD}$ and persistent rise in BP (Fig. 1). Titration of the perfusate with $10 \mathrm{mM} \mathrm{HCI}$ at $\mathrm{pH} 7.0$ revealed the production of about $0.2-0.4$ $\mu \mathrm{Eq}$ of $\mathrm{HCO}_{3}{ }^{-}$every $5 \mathrm{~min}$, and this rate was well- 

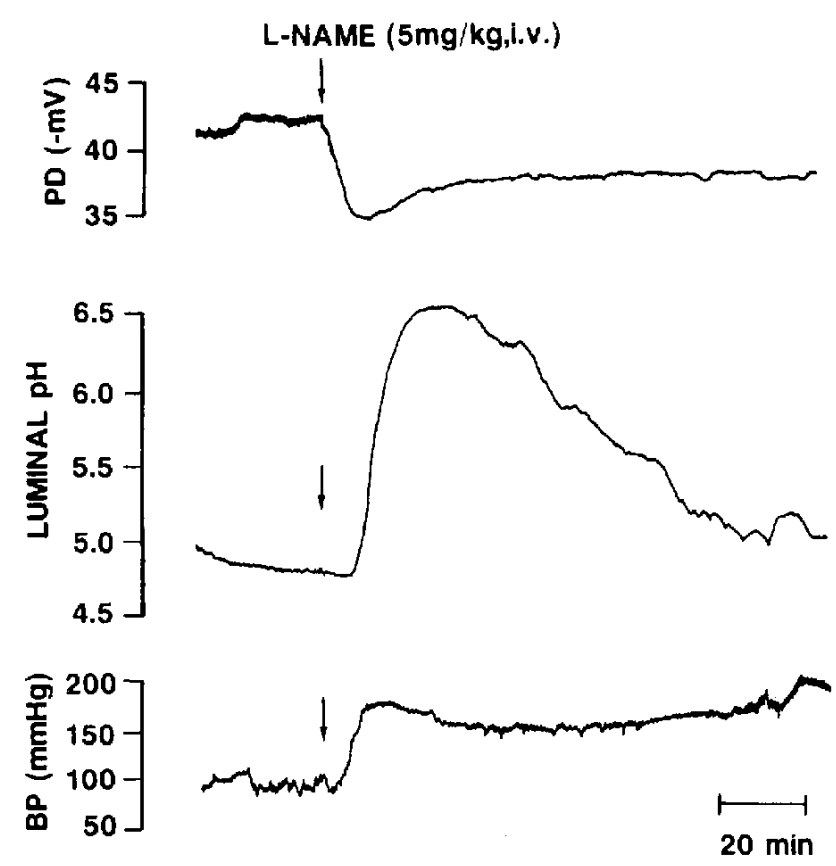

Fig. 1. Representative recordings of changes in $\mathrm{PD}$ and $\mathrm{pH}$ of the chambered stomach simultaneously with systemic BP in an anesthetized rat after i.v.-administration of L-NAME $(5 \mathrm{mg} / \mathrm{kg})$. The mucosa was perfused with acidified saline $(\mathrm{pH} 4.5)$ under acid inhibition by omeprazole $(60 \mathrm{mg} / \mathrm{kg}$, i.p.). Note that the luminal $\mathrm{pH}$ was increased markedly after administration of L-NAME with a slight decrease in $\mathrm{PD}$ and persistent elevation of $\mathrm{BP}$.

maintained during the 90 min-test period. Administration of L-NAME $(1,2.5$ and $5 \mathrm{mg} / \mathrm{kg})$ increased gastric $\mathrm{HCO}_{3}$ output significantly in a dose-related manner, and this secretion at $5 \mathrm{mg} / \mathrm{kg}$ reached maximal levels $(0.85 \pm 0.16 \mu \mathrm{Eq} / 5 \mathrm{~min})$ of 4 times greater than the basal values $(0.23 \pm 0.03 \mu \mathrm{Eq} / 5 \mathrm{~min})$ and remained elevated for $1 \mathrm{hr} ; \Delta \mathrm{HCO}_{3}{ }^{-}$output was $5.6 \pm 1.0$ $\mu \mathrm{Eq} / \mathrm{hr}$, which is almost equivalent to that $(4.8 \pm 1.0$ $\mu \mathrm{Eq} / \mathrm{hr}$ ) induced by $\mathrm{PGE}_{2}(0.3 \mathrm{mg} / \mathrm{kg}$ ) (Fig. $2, \mathrm{~A}$ and B). Gastric $\mathrm{HCO}_{3}{ }^{-}$secretion was also stimulated significantly by another NO synthase inhibitor, L-NMMA $(50 \mathrm{mg} / \mathrm{kg}), \Delta \mathrm{HCO}_{3}{ }^{-}$output being $2.4 \pm 0.7 \mu \mathrm{Eq} / \mathrm{hr}$. On the other hand, the stimulatory effect of L-NAME $(5 \mathrm{mg} / \mathrm{kg})$ on gastric $\mathrm{HCO}_{3}{ }^{-}$secretion was significantly antagonized by pretreatment with L-arginine $(200$ $\mathrm{mg} / \mathrm{kg}$, i.v.) at the dose which partially mitigated the rise in BP seen after administration of L-NAME (\%increase in BP at 5 min-post treatment: $41.7 \pm 2.6 \%$ vs. $26.4 \pm 4.6 \%, \mathrm{P}<0.05$ ). In the rats pretreated with L-arginine, the $\Delta \mathrm{HCO}_{3}{ }^{-}$output induced by L-NAME was $1.3 \pm 0.6 \mu \mathrm{Eq} / \mathrm{hr}$, which is about $23.2 \%$ of the $\Delta \mathrm{HCO}_{3}{ }^{-}$output obtained in control animals given LNAME alone. D-Arginine did not affect the increased $\mathrm{HCO}_{3}{ }^{-}$response to L-NAME.

The present study showed that gastric $\mathrm{HCO}_{3}{ }^{-}$secre-
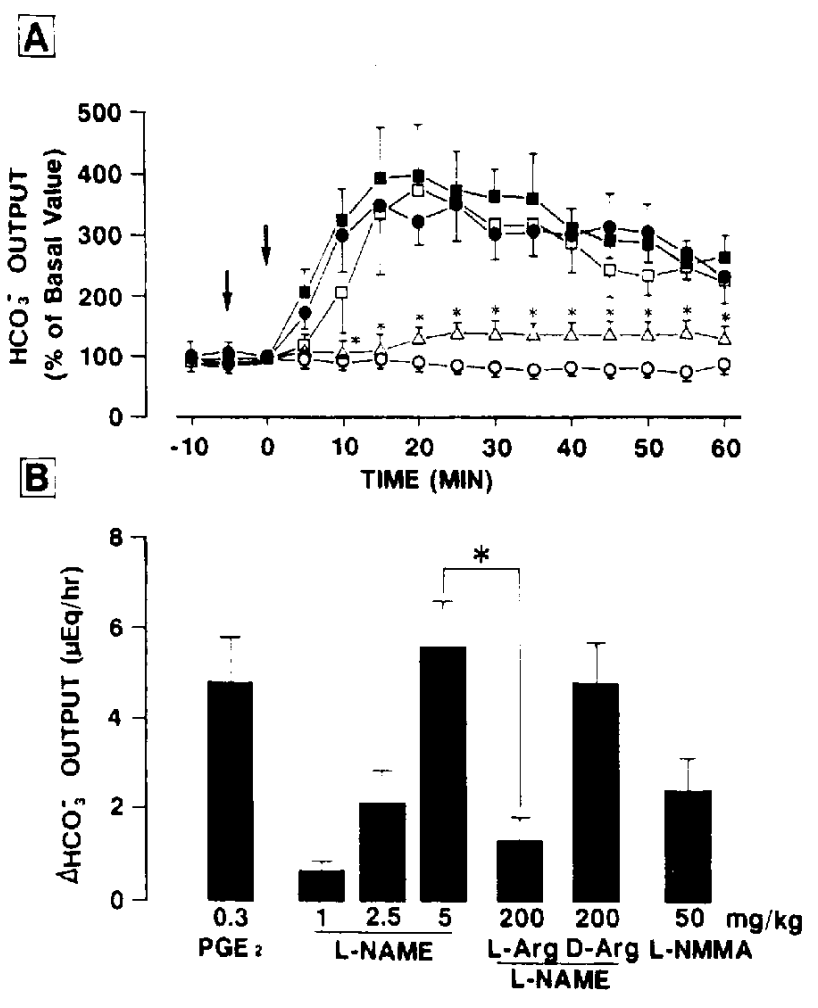

Fig. 2. Effects of L-NAME $(5 \mathrm{mg} / \mathrm{kg})$, L-NMMA $(50 \mathrm{mg} / \mathrm{kg})$, $\mathrm{PGE}_{2}(0.3 \mathrm{mg} / \mathrm{kg})$ and $\mathrm{L}$ - or D-arginine $(200 \mathrm{mg} / \mathrm{kg})$ plus $\mathrm{L}$ NAME $(5 \mathrm{mg} / \mathrm{kg})$ on $\mathrm{HCO}_{3}{ }^{-}$secretion in the stomachs of anesthetized rats $[\mathrm{A}]$ and the net $\mathrm{HCO}_{3}{ }^{-}$output induced by these treatments [B]. Each agent was given i.v. after basal secretion had stabilized. L-Arginine or D-arginine was given $5 \mathrm{~min}$ before administration of L-NAME. [A]: Data are expressed as a $\%$ of the basal values (time 0 ) and represent the means $\pm S$.E. of valucs determined every $5 \mathrm{~min}$ from $5-6$ rats $\left(O\right.$ saline, $O \mathrm{PGE}_{2}$, $\square \mathrm{L}-$ NAME, $\triangle$ L-arginine plus L-NAME, $\square$ D-arginine plus LNAME). [B]: Values indicate the net $\mathrm{HCO}_{3}{ }^{-}$output obtained for $1 \mathrm{hr}$ after the treatments and represent the means \pm S.E. from 56 rats. *Statistically significant difference from the group given $\mathrm{L}$ NAME alone, at $\mathrm{P}<0.05$.

tion was significantly stimulated by the NO synthase inhibitor L-NAME in the anesthetized rats. It is unlikely that the increase of luminal alkalinization by L-NAME is brought about by an inhibition of acid secretion, because in this study, $\mathrm{HCO}_{3}{ }^{-}$secretion was measured in the animals pretreated with omeprazole, by which acid secretion had been completely blocked. On the other hand, the effect of L-NAME on $\mathrm{HCO}_{3}{ }^{-}$secretion may appear through inhibition of NO biosynthesis but is not attributable to the non-specific action of this agent. This contention is supported by the following findings: (a) another NO synthase inhibitor, L-NMMA, increased gastric $\mathrm{HCO}_{3}$ secretion similar to L-NAME and (b) the effect of L-NAME was significantly antagonized by concurrent administration of $\mathrm{L}$-arginine but not by $\mathrm{D}$-arginine. In a preliminary study, we also found 
that L-NAME increased $\mathrm{HCO}_{3}{ }^{-}$secretion in the rat duodenum and that this effect was significantly antagonized by L-arginine or the exogenous NO donner nitroprusside (unpublished data, K. Takeuchi et al.). These results suggest that $\mathrm{NO}$ may be involved as the endogenous inhibitor in the regulation of $\mathrm{HCO}_{3}$ secretion. The increased $\mathrm{HCO}_{3}{ }^{-}$responses induced by $\mathbf{L}-$ NAME were accompanied by the decrease in gastric $\mathrm{PD}$ and the persistent rise in systemic BP. Kubes and Granger (6) reported that inhibition by L-NAME of NO production by vascular endothelium leads to a reversible rise in microvascular protein efflux in the cat ileum. Although the mechanism by which the inhibition of $\mathrm{NO}$ biosynthesis increased $\mathrm{HCO}_{3}$ secretion remains unknown, it might be assumed that these phenomena are causally-related to the increased $\mathrm{HCO}_{3}{ }^{-}$responses to L-NAME. Certainly, since other vasopressor agents such as norepinephrine and vasopressin are known to inhibit $\mathrm{HCO}_{3}{ }^{-}$secretion $(7,8)$, it is unlikely that the elevation of $\mathrm{BP}$ simply leads to an increase of $\mathrm{HCO}_{3}{ }^{-}$ secretion.

In general, $\mathrm{HCO}_{3}{ }^{-}$secretion is considered as one of the defensive factors in the stomach as well as in the duodenum $(9,10)$. The present results seem to be inconsistent with the protective role of NO in the gastric mucosa. The $\mathrm{HCO}_{3}{ }^{-}$secretion in the stomach is known to increase in response to vagal excitation or agents that stimulate acid secretion $(11,12)$. Barrachina et al. (13) recently reported that L-NAME significantly reversed the antisecretory effect of endotoxin on distention-stimulated acid output and suggested the involvement of $\mathrm{NO}$ in the regulation of acid secretion. If $\mathrm{HCO}_{3}{ }^{-}$secretion is physiologically important as an acid-neutralizing factor, it would be understandable that $\mathrm{NO}$ suppresses the "protective $\mathrm{HCO}_{3}$ " as well as the "aggressive $\mathrm{H}^{+}$" secretions.

The present study showed for the first time that the administration of L-NAME stimulates gastric $\mathrm{HCO}_{3}{ }^{-}$ secretion in anesthetized rats, although the mechanisms responsible for this phenomenon have not been fully evaluated yet. Further studies to elucidate the role of $\mathrm{NO}$ in the regulation of $\mathrm{HCO}_{3}{ }^{-}$secretion are warranted.

\section{REFERENCES}

1 Moncada, S., Palmer, R.M.J. and Higgs, E.A.: Nitric oxide: Physiology, pathophysiology and pharmacology. Pharmacol. Rev. 43, $109-142$ (1991)

2 Pique, J.M., Whittle, B.J.R. and Esplugues, J.V.: The vasodilator role of endogenous nitric oxide in the rat gastric microcirculation. Eur. J. Pharmacol. 174, 293-296 (1989)

3 Whittle, B.J.R., Lopes-Bermonte, J. and Moncada, S.: Regulation gastric mucosal integrity by endogenous nitric oxide: Interactions with prostanoids and sensory neuropeptides in the rat. Br. J. Pharmacol. 99, 607-611 (1990)

4 Lippe, I.Th. and Holzer, P.: Participation of endotheliumderived nitric oxide but not prostacyclin in the gastric mucosal hyperemia due to acid back-diffusion. Br. J. Pharmacol. 105, 708- 714 (1992)

5 Takeuchi, K., Ueshima, K., Matsumoto, J. and Okabe, S.: Role of capsaicin-sensitive sensory nerves in acid-induced bicarbonate secretion in rat stomach. Dig. Dis. Sci. 37, $737-743$ (1992)

6 Kubes, P. and Granger, D.N.: Nitric oxide modulates microvascular permeability. Am. J. Physiol. 262, H611-H615 (1992)

7 Nylander, O. and Flemstrom, G.: Effects of alpha-adrenoceptor agonists and antagonists on duodenal surface epithelial $\mathrm{HCO}_{3}{ }^{-}$secretion in vivo. Acta Physiol. Scand. 130, 387-391 (1987)

8 Lenz, H.J., Forquignon, I., Druge, G. and Greten, H.: Effects of neuropeptides on gastric acid and duodenal bicarbonate secretions in freely moving rats. Regul. Pept. 24 , 293-300 (1989)

9 Flemstrom, G. and Turnberg, L.A.: Gastroduodenal defense mechanisms. Clin. Gastroenterol. 13, $327-354$ (1984)

10 Garner, A., Flemstrom, G., Allen, A., Heylings, J.R. and McQueen, S.: Gastric mucosal protective mechanism: Roles of cpithelial bicarbonate and mucus secretions. Scand. J. Gastroenterol. 19, 79-86 (1984)

11 Fandriks, L.: Vagal and splanchnic neural influences on gastric and duodenal bicarbonate secretions. Acta Physiol. Scand. 128, Supp. 1-39 (1986)

12 Takeuchi, K., Ueshima, K. and Okabe, S.: Stimulation of gastric bicarbonate secretion by an analog of thyrotropinreleasing hormone, YM-14673, in the rat. J. Pharmacol. Exp. Ther. 256, $1057-1062$ (1991)

13 Barrachina, M.D., Esplugues, J.V., Martinez-Cuesta, M.A., Pique, J.M. and Whittle, B.J.R.: Nitric oxide modulates the inhibition by endotoxin of distention-stimulated gastric acid secretion (abstract). Gastroenterology 92, 1759 (1992) 